\title{
DISCURSOS DOCENTES DO CURSO DE PEDAGOGIA: UM OLHAR À LUZ DA TEORIA DA ARGUMENTAÇÃO
}

\author{
DISCURSOS DOCENTES DE LA CARRERA DE PEDAGOGÍA: CONSIDERACIONES \\ BAJO LA LUZ DE LA TEORÍA DE LA ARGUMENTACIÓN
}

\author{
DISCOURSES OF TEACHERS OF THE PEDAGOGY COURSE: A LOOK IN THE \\ LIGHT OF THE THEORY OF ARGUMENTATION
}

\author{
Clara Corrêa da COSTA ${ }^{1}$ \\ Helen Silveira Jardim de OLIVEIRA ${ }^{2}$
}

RESUMO: Este artigo é inspirado em duas pesquisas concluídas de Pós-Graduação em Educação - uma de doutorado e outra de pós-doutorado - cuja fundamentação teóricometodológica é ancorada na Teoria da Argumentação, concebida por Chaïm Perelman e Lucie Olbrechts-Tyteca, em 1958. Ambas as pesquisas se conectam, pois tratam de reflexões, problematizações e acordos provisórios sobre temáticas que envolvem a Educação na contemporaneidade. Este trabalho se propõe a apresentar possibilidades de articulação da Teoria da Argumentação à Educação, tal como proposto por Lemgruber e Oliveira (2011), Mazzotti (2011); Castro, Maia e Alves-Mazzotti (2013) e Castro (2016). Para tal, focalizamos a formação pedagógica no discurso de professores de curso de Pedagogia. A partir das reflexões teóricas realizadas da análise argumentativa empreendida, entendemos que o atual modelo de formação ainda não constitui base de conhecimento que articule os conhecimentos teóricos às práticas pedagógicas que orientarão o futuro professor em sua atuação na Educação Infantil e dos anos iniciais do Ensino Fundamental, levando em conta suas especificidades. Embora haja na literatura um consenso acerca da imprescindibilidade de alteração na estrutura do curso de Pedagogia, em que a docência constitua efetivamente o foco de atuação dos professores desse curso, essa é uma questão que ainda não foi solucionada. Compreendendo a Educação como um campo propício a aprimoramentos e mudanças, este trabalho busca colaborar com a construção de conhecimentos na área de Educação, oferecendo, na medida do possível, subsídios para estudos que versem sobre a Formação Docente a partir das contribuições oriundas dos autores da área da Argumentação.

PALAVRAS-CHAVE: Formação docente. Formação pedagógica. Argumentação. Discursos docentes. Pedagogia.

RESUMEN: Este artículo se inspira en dos investigaciones concluidas en el Posgrado en Educación - una de doctorado y otra de postdoctorado - cuya fundamentación teóricometodológica se basa en la Teoría de la Argumentación, concebida por Chaïm Perelman y

\footnotetext{
${ }^{1}$ Colégio Pedro II (CPII), São Cristóvão I, Rio de Janeiro - RJ - Brasil. Professora do Ensino Básico Técnico e Tecnológico. Departamento de Anos Iniciais do Ensino Fundamental. Doutora em Educação (UNESA). ORCID: https://orcid.org/0000-0003-2717-4126. E-mail: correa.clara@outlook.com

${ }^{2}$ Colégio Pedro II (CPII), Campus São Cristóvão I, Rio de Janeiro - RJ - Brasil. Professora do Ensino Básico Técnico e Tecnológico. Departamento de Anos Iniciais do Ensino Fundamental. Pós-doutora em Educação (UFRJ). ORCID: https://orcid.org/0000-0002-3738-9529. E-mail: prof_helen@yahoo.com.br
} 
Lucie Olbrechts-Tyteca, en 1958. Las dos investigaciones se conectan, ya que tratan de reflexiones, problematizaciones y acuerdos provisionales sobre temáticas que involucran la Educación en la actualidad. Este trabajo propone presentar posibilidades de articulación de la Teoría de la Argumentación a la Educación; tal como propuesto por Lemgruber y Oliveira (2011), Mazzotti (2011); Castro, Maia y Alves-Mazzotti (2013) y Castro (2016). Para ello, enfocamos la formación pedagógica en el discurso del profesorado en la carrera de Pedagogía. A partir de las reflexiones teóricas realizadas del análisis argumentativo emprendido, comprendemos que el actual modelo de formación todavía no constituye base de conocimiento que articule los conocimientos teóricos a las prácticas pedagógicas que orientarán el futuro profesor en su actuación en la Enseñanza Infantil y de los primeros años de la Enseñanza Primaria, teniendo en cuenta sus especificidades. Aunque haya un consenso en la literatura acerca de la necesidad de alteración en la estructura de los profesores de este curso, esta es una cuestión que todavía no se ha solucionado. Comprendiendo la Educación como un campo propicio a perfeccionamientos y cambios, este trabajo busca colaborar con la construcción de conocimientos en el área de la Educación, ofreciendo, en la medida de lo posible, subsidios para estudios que versen sobre la Formación Docente a partir de las contribuciones oriundas de los autores del área de la Argumentación.

PALABRAS CLAVE: Formación docente. Formación pedagógica. Argumentación. Discursos docentes.

ABSTRACT: This paper is inspired by two concluded post-graduate researches in Education - one of doctorate and the other of post-doctoral - whose theoretical-methodological basis is anchored in the Theory of Argumentation, conceived by Chaïm Perelman and Lucie Olbrechts-Tyteca, in 1958. Both researches are connected, since they deal with reflections, problematizations and provisional agreements on themes that involve Education in contemporaneity. This work proposes to present possibilities of articulation of the Theory of Argumentation to Education, as proposed by Lemgruber and Oliveira (2011), Mazzotti (2011); Castro, Maia and Alves-Mazzotti (2013) and Castro (2016). Therefore, we focus on pedagogical training in the discourse of teachers of Pedagogy courses. From the theoretical reflections carried out from the argumentative analysis conducted, we understand that the current training model still does not constitute a knowledge base that links theoretical knowledge to the pedagogical practices that will guide the future teacher in his performance in Early Childhood Education and the initial years of Elementary School, taking into account their specificities. Although there is a consensus in the literature about the indispensability of changing the structure of the Pedagogy course, in which teaching effectively constitutes the focus of the teachers of this course, this is an issue that has not yet been resolved. Understanding Education as a field conducive to improvement and change, this work seeks to collaborate with the construction of knowledge in the area of Education, offering, as far as possible, subsidies for studies that address the Teacher Training from the contributions provided by the authors of the area of Argumentation.

KEYWORDS: Teacher training. Pedagogical training. Argumentation. Discourses of teachers. Pedagogy. 


\section{Introdução}

Este artigo é inspirado em duas pesquisas concluídas de Pós-Graduação na área da Educação - uma de doutorado e outra de pós-doutorado - cuja fundamentação teóricometodológica é ancorada na Teoria da Argumentação, concebida por Chaïm Perelman e Lucie Olbrechts-Tyteca, em 1958. Destacamos que autores como Lemgruber e Oliveira (2011), Mazzotti (2011); Castro, Maia e Alves-Mazzotti (2013) e Castro (2016) também estudaram e ampliaram a teoria, realizando articulações à Educação.

A primeira pesquisa, de abordagem qualitativa (PATTON, 2002), teve como objetivo identificar, analisar e comparar as representações sociais de formação pedagógica no discurso de professores de curso de Pedagogia que atuam em universidades públicas e privadas do Rio de Janeiro e em documentos legais. Recorreu-se à Teoria da Argumentação por possibilitar uma investigação com base no discurso a partir da intenção do locutor de persuadir seu auditório, explicitando os momentos de negociação de significados dos interlocutores, normalmente implícitos no discurso.

A partir do desenvolvimento da pesquisa, foi possível identificar diversos elementos que dificultam o desenvolvimento de uma formação pedagógica no curso de Pedagogia que dê ao futuro professor a base necessária para lidar, com autonomia, com os desafios que poderão surgir ao longo de sua prática docente. São eles: a maneira segmentada como a legislação para a formação de professores foi sendo implementada; as características dos currículos dos cursos, que mantêm uma formação panorâmica, em função da ampla complexidade curricular exigida para o curso e a viabilidade de tempo necessário para o seu desenvolvimento; e o apego à tradição do antigo bacharelado, presente na prática de professores de curso de Pedagogia.

Com base nesses aspectos, foi possível concluir que prevalece uma ênfase teórica à formação pedagógica, desenvolvida de forma generalista, em detrimento de conhecimentos tanto de cunho específico, quanto pedagógico. A articulação desses conhecimentos, que deveria nortear a formação de professores, acaba sendo relegada a segundo plano. Tais fatos são preocupantes, pois as consequências dessa ênfase ainda são constatadas com relativa frequência na contemporaneidade, quando os educadores iniciam sua vida profissional.

Já a segunda pesquisa, do tipo bibliográfico (MARCONI; LAKATOS, 2018), investigou, a partir da Teoria da Argumentação proposta por Perelman e Olbrechts-Tyteca (2005) e da Problematologia concebida por Meyer (2002), as nuances existentes entre relações argumentativas e dialógicas que ocorrem no espaço educacional, especificamente 
entre docentes e discentes, observando também como ocorre tal construção. Para tanto, foram analisadas em profundidade as contribuições teóricas da Retórica e da Argumentação e apresentadas proposições à Educação.

Em linhas gerais, essa investigação concluiu que: dialogar e argumentar não significa "não sistematizar" algumas decisões; a perspectiva dialógica e argumentativa não é unilateral; a heterogeneidade dos auditórios não deve ser considerada um problema, mas algo complementar; a negociação de distâncias pode se constituir num caminho pertinente e promissor que será aperfeiçoado no seu constante exercício, podendo acarretar soluções plausíveis - razoáveis - para os diversos conflitos na Educação.

A partir das considerações realizadas até aqui, percebemos que ambas as pesquisas se conectam, pois tratam de reflexões, problematizações e acordos, ainda que provisórios, temáticas que envolvem a Educação. Debruçar-se sobre a relação educador e educando na escola, ou sobre as representações sociais de formação pedagógica no discurso de professores de curso de Pedagogia, às quais iremos privilegiar neste artigo, é admitir a existência constante de uma multiplicidade de opiniões, conflitos, divergências e, também, consensos entre os mais diferentes auditórios particulares. Nesse sentido, a racionalidade argumentativa é profícua para enveredar pelo terreno do plausível, do duvidoso, do diverso, no qual não há certezas e, sim, caminhos.

Por fim, compreendendo a Educação como um campo propício a aprimoramentos e mudanças, este artigo busca colaborar com a construção de conhecimentos na área de Educação, oferecendo, na medida do possível, subsídios para estudos que versem sobre a Formação Docente, a partir das contribuições oriundas dos autores da Argumentação.

\section{A teoria da argumentação: articulações à Educação}

O Tratado da Argumentação (T.A.), escrito por Perelman (1912-1984) e OlbrechtsTyteca (1899-1987), em 1958, é uma obra de referência, pois apresenta os fundamentos filosóficos do arcabouço teórico desenvolvido por eles, denominado de Teoria da Argumentação, também conhecida por Nova Retórica devido à reabilitação do sistema retórico grego, essencialmente proposto por Aristóteles.

Perelman, com influência da sua formação em Lógica e em Direito, relaciona algumas ideias provenientes do raciocínio jurídico à Filosofia, valendo-se de um modelo jurídico aplicando-o à Argumentação. Nesse sentido, segundo o próprio, as questões podem ser retomadas e é possível retornar a um julgamento, pois o modelo jurídico permite essa 
flexibilidade. Tal pensamento é justamente o oposto do modelo geométrico que é utilizado por Platão, por exemplo, no qual uma questão não pode ser reaberta. Uma discussão sob o viés platônico é realizada de forma dicotômica, ou seja, no desenvolvimento desse tipo de argumentação, ao se adotar um caminho e, dado um "consenso", prossegue-se a discussão de modo linear, não sendo mais possível retornar a alguma questão. Esse modelo incorpora uma perspectiva demonstrativa, muito utilizada pela Matemática.

Perelman e Olbrechts-Tyteca (2005) não se dedicaram à articulação da sua teoria com a Educação, porém, nas páginas 57 a 60 do T.A., eles discutem acerca da diferença entre o discurso utilizado na Educação e na propaganda. Eis um fragmento:

Enquanto o propagandista deve granjear, previamente, a audiência de seu público, o educador foi encarregado por uma comunidade de tornar-se o porta-voz dos valores reconhecidos por ela e, como tal, usufrui um prestígio devido a suas funções (PERELMAN; OLBRECHTS-TYTECA, 2005, p. 58).

Concordamos com os autores do T.A. quando afirmam que o educador usufrui de um prestígio, pois, geralmente, os docentes são considerados uma referência, um modelo a ser seguido, cujos argumentos têm credibilidade e valor na sociedade, todavia não podemos generalizar. Em relação ao fato de os educadores serem os porta-vozes dos valores reconhecidos por um grupo, assentimos parcialmente pois, em muitas situações, o docente pode ser porta-voz dos seus próprios interesses, dos interesses da instituição de ensino, da sociedade e, não, do interesse de outrem, como dos discentes. Reconhecemos, portanto, que a época e as concepções sobre ser educador no momento em que a referida obra foi escrita são diferentes da atualidade.

Neste momento, pretendemos discorrer sobre algumas categorias teóricas apresentadas no Tratado da Argumentação, tentando promover algumas inter-relações com a Educação.

Sobre os propósitos da argumentação, Perelman e Olbrechts-Tyteca abordam que “[...] toda argumentação visa à adesão dos espíritos e, por isso mesmo, pressupõe a existência de um contato intelectual" (2005, p. 16, grifo dos autores). Portanto, podemos dizer que o processo educativo não é algo ingênuo, nem inconsciente. Há um contato racional entre oradores e auditórios.

Conforme Perelman e Olbrechts-Tyteca (2005, p. 22), é “[...] preferível definir o auditório como o conjunto daqueles que o orador quer influenciar com sua argumentação" (grifo dos autores). Os referidos autores também afirmam que "É, de fato, ao auditório que 
cabe o papel principal para determinar a qualidade da argumentação e o comportamento dos oradores" (2005, p. 27).

Consideramos que estudantes, professores e instituições de ensino ora exercem a função de oradores e ora atuam como auditórios, com interesses e necessidades peculiares que estão, constantemente, em um ambiente de negociação de sentidos e de distâncias (MEYER, 2002). Ou seja, as posições de orador e auditório não são estagnadas, mas devem ser compartilhadas consoante o desenvolvimento da argumentação.

Com base em Perelman e Olbrechts-Tyteca (2005), há diferentes tipos de auditórios. Pensando no recorte deste trabalho, cremos que os professores do curso de Pedagogia constituam um auditório particular, por comungarem o mesmo ofício, e, em alguma medida, a mesma formação. De certo modo, também podem ser considerados um auditório de elite, por serem especialistas em determinados assuntos. Além disso, pelo fato de terem sido convidados a apresentarem discursos, opiniões e argumentos acerca da Formação Docente, são considerados oradores em busca de adesão às teses apresentadas.

[...] os auditórios variam muito em composição e extensão. Podemos ter auditórios particulares (professores, médicos, católicos, socialistas, etc.), auditórios de elite (que buscam se colocar como modelos para outros auditórios) e mesmo o auditório universal, que encarna a visão do orador do conjunto dos homens razoáveis. O auditório universal não é uma realidade física, mas antes a expressão de uma determinada imagem do homem construída pelo orador (OLIVEIRA, 2011, p. 19).

De acordo com Perelman (2004), auditórios e oradores são grupos heterogêneos. Não devemos permitir que a heterogeneidade se torne um problema, gerando ou reforçando incompatibilidades, mas que a mesma seja uma aliada. Logo, é fundamental que o orador procure conhecer os auditórios com os quais lida (seu meio sociocultural, suas características, seus interesses) e busque também o seu autoconhecimento. Um bom orador é aquele que tem a capacidade de equilibrar e ponderar suas habilidades e limitações junto ao auditório, articulando-as da melhor maneira possível. Consideramos que tais ações podem fazer toda a diferença no diálogo.

Compreendemos que o professor, ao exercer o papel de orador, deve estar atento a essas ações e que, em certas situações, ele deve se preparar antes de iniciar uma discussão. A tomada de consciência a respeito das características, qualidades e limitações pessoais (quando se desempenha o papel de orador) e do outro (quando se desempenha o papel de auditório) pode subsidiar o desenvolvimento da argumentação. Oradores e auditórios podem se 
diferenciar em muitos aspectos, porém entendemos que esses, ao invés de se confrontarem, podem se complementar de modo positivo, trazendo riqueza ao processo argumentativo.

Tratando de algumas características da argumentação, podemos afirmar que ela não deve ser coerciva e, para que se inicie, deve existir um acordo prévio, que é uma espécie de consenso inicial. Em suma, os objetos de acordo são o ponto de partida para a argumentação, destacando que o acordo sempre é passível de ser questionado, revitalizado ou modificado, isto é, ele é flexível. Este acordo preliminar é compreendido por Lemgruber e Oliveira (2011, p. 43) como condições prévias:

Mas, disposição para ouvir é muito mais do que apenas escutar. É ter apreço pelo que o outro tem a dizer. Essa é a grande sintonia da teoria da argumentação com as pedagogias dialógicas: a realização da regra segundo a qual o orador deve partir do que é admitido pelo auditório enquanto valorização dos saberes prévios dos educandos. Se adaptar-se ao auditório é, principalmente, adotar como premissas da argumentação as teses por ele admitidas $[\ldots]$

Os objetos de acordo são agrupados pelos autores em duas categorias: uma relativa ao real e outra relativa ao preferível. A categoria relativa ao real engloba os fatos, as verdades e as presunções. Já a categoria que se refere ao campo do preferível abarca os valores, que podem ser abstratos e concretos, as hierarquias, os lugares da quantidade, da qualidade e outros. O campo do real seria uma pretensão de validade para o auditório universal, enquanto o campo do preferível se identifica com o ponto de vista determinado de um auditório particular, ainda que o mesmo seja amplo.

Não detalharemos cada um desses objetos de acordo, pois correríamos o risco de sintetizar um tópico do T.A. que merece um desenvolvimento mais rico e aprofundado. É válido ratificar que ao assumir o papel de oradores temos de estar atentos a esses objetos, visto que não existe argumentação possível sem algum acordo prévio entre orador e auditório.

Os objetos de acordo se colocam como condições prévias para que o orador possa argumentar visando à persuasão do auditório. Se não houver o compartilhamento de tais objetos, os raciocínios concatenados por quem se propõe a argumentar caem em uma espécie de vazio, semelhante ao que ocorre em um sistema formal quando os pressupostos que configuram o ponto de partida da demonstração não são aceitos (OLIVEIRA, 2011, p. 2223).

Ressaltamos que o objetivo do T.A. não foi criar um inventário sobre tudo o que se pode tornar objeto de acordo e, sim, organizar o olhar sobre esses elementos e discuti-los, a fim de propiciar um maior entendimento sobre a Teoria da Argumentação. 
$\mathrm{Na}$ terceira parte do T.A, os autores enfocam as técnicas argumentativas. Eles procuram organizar o tipo de argumentação que é utilizada, não limitando-a a esquemas de classificação rígidos. Os esquemas argumentativos propostos por Perelman e OlbrechtsTyteca (2005) caracterizam-se pela ligação ou pela dissociação.

Os processos de ligação são aqueles que buscam a solidariedade entre as partes, ou seja, que pretendem ligar elementos que a princípio estão separados na argumentação. São assim tipificados: argumentos quase-lógicos, baseados na estrutura do real e os que fundam a estrutura do real.

Os argumentos quase-lógicos “[...] pretendem certa força de convicção, na medida em que se apresentam como comparáveis a raciocínios formais, lógicos ou matemáticos” (PERELMAN; OLBRECHTS-TYTECA, 2005, p. 219). Esses argumentos parecem mostrar verdades, todavia, em se tratando do campo argumentativo, suas conclusões serão sempre verossímeis, ou seja, com força de verdade. A tautologia, argumento em que nenhum elemento novo é acrescentado; a incompatibilidade, utilizada pelo orador para mostrar teses opostas e a necessidade de escolha da melhor a ser aplicada à determinada situação e a implicação lógica, afirmação coerente, não evidente, que pode ser justificada argumentativamente, são recursos usados pelos oradores neste grupo de argumentos.

Os argumentos baseados na estrutura do real recorrem aos acordos que são promovidos sobre o real para estabelecer solidariedade entre as partes. Esse tipo de argumentação invoca uma ligação que já existe, justificando elementos conhecidos. Neste grupo de argumentos, estão incluídas as ligações de sucessão, que englobam os vínculos causais (meio/fim, fato/consequência, causa/efeito) e as ligações de coexistência (PERELMAN; OLBRECHTS-TYTECA, 2005). Eis um exemplo: Um estudante realiza todas as tarefas de casa e os trabalhos solicitados pelo professor, por isso, terá uma avaliação satisfatória na disciplina. Nesse caso, podemos observar um vínculo estabelecido entre o ato do discente e sua possível consequência.

Os argumentos que fundam a estrutura do real se valem do conhecido para se alcançar o desconhecido. Ou seja, nesse caso o objetivo é estabelecer vínculo entre algo que se conhece para se apreender a realidade almejada. Isso pode ser realizado através de exemplos, ilustrações, modelos ou pela analogia e as figuras retóricas oriundas delas, as metáforas (OLIVEIRA, 2011). Um exemplo desse tipo de argumento é: o conhecimento é o alimento para a alma. Desta forma, a analogia de origem é conhecimento/alma (termos A e B) e alimento/corpo (temos C e D). 
Contrapondo-se aos esquemas de ligação, temos os processos de dissociação, que são “[...] técnicas de ruptura com o objeto de dissociar, de separar, de desunir elementos considerados um todo, ou pelo menos um conjunto solidário dentre de um mesmo sistema de pensamento" (PERELMAN; OLBRECHTS-TYTECA, 2005, p. 215). A dissociação realiza esse processo modificando algumas noções, mostrando sua inadequação, ou então, apresentando uma faceta que não tivesse sido pensada até um dado momento. Essas duas técnicas são complementares e são utilizadas pelo orador de acordo com o objetivo da sua argumentação. Um exemplo de dissociação é: "há professores e professores". Apesar da repetição do termo "professores", há uma distinção clara que se pode inferir. Ao proferir de forma mais enfática o primeiro ou o segundo termo, o orador pode sugerir ao auditório que há professores melhores que outros, de acordo com o mérito, a conduta, a formação, a didática, a metodologia, por exemplo.

\section{O modelo de estratégia argumentativa: uma ferramenta de análise do discurso em Educação}

Com a preocupação de buscar uma ferramenta para analisar os dados obtidos de pesquisas centradas nos processos discursivos e comunicacionais em Educação, Monica Rabello de Castro e Janete Bolite-Frant desenvolveram, em 1995, o Modelo de Estratégia Argumentativa (MEA), tendo como base a Teoria da Argumentação.

Até hoje, o MEA tem sido aplicado em diferentes situações de pesquisa em Educação, focalizando o discurso de professores, alunos e demais profissionais dessa área em contextos interativos de aprendizagem.

Por tratar-se de um trabalho de reconstrução de argumentos, a análise da estratégia argumentativa requer uma organização esquemática do argumento que está sendo utilizado pelo orador, feita por meio de enunciados simples que o resumam. Para tal, Castro e BoliteFrant (2011) sinalizam a necessidade de partir sempre da identificação das controvérsias que se fazem presentes no discurso.

Consideramos imprescindível salientar que o conceito de controvérsia, tal como proposto pelas autoras para o desenvolvimento da análise por meio do MEA, se diferencia do entendimento do senso comum, utilizado cotidianamente. Os enunciados controversos são, geralmente, identificados em situações em que o orador tem a possibilidade de se posicionar contra ou a favor de determinado assunto, sendo explicitados pela necessidade que demonstra ter de se justificar. 
Assim, deve-se destacar a tese, elaborada em torno de uma situação de controvérsia, as premissas que dão sustentação à tese e o modo como essas premissas se associam à tese. A Figura 1 apresenta um esquema simplificado para a montagem de um argumento, como sugerido pelas autoras:

Figura 1 - Esquema simplificado para a montagem de um argumento

\section{Premissa 1 Premissa 2 Premissa 3}

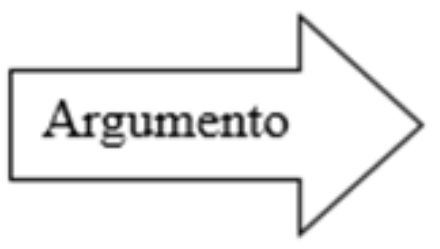

\section{TESE}

Fonte: Castro e Bolite Frant (2011)

As autoras enfatizam que o MEA se constitui de dois processos de montagem: um engendrado pelos participantes da pesquisa e outro pela interpretação da fala desses sujeitos ou do material escrito por parte do pesquisador, uma vez que não se pode apresentar o que o outro disse apenas repetindo o que foi dito. Sendo assim, o trabalho da estratégia argumentativa:

[...] será o de reconstruir os argumentos, descrevendo esquemática e resumidamente qual argumento foi utilizado, relacionando com outros argumentos, para poder explicar sua existência, classificá-lo e explicar sua posição na composição de um discurso coerente. (CASTRO; BOLITEFRANT, 2011, p. 78).

A Figura 2, apresentada a seguir, ilustra a montagem da Estratégia Argumentativa, conforme proposta pelas autoras:

Figura 2 - Esquema de montagem da Estratégia Argumentativa

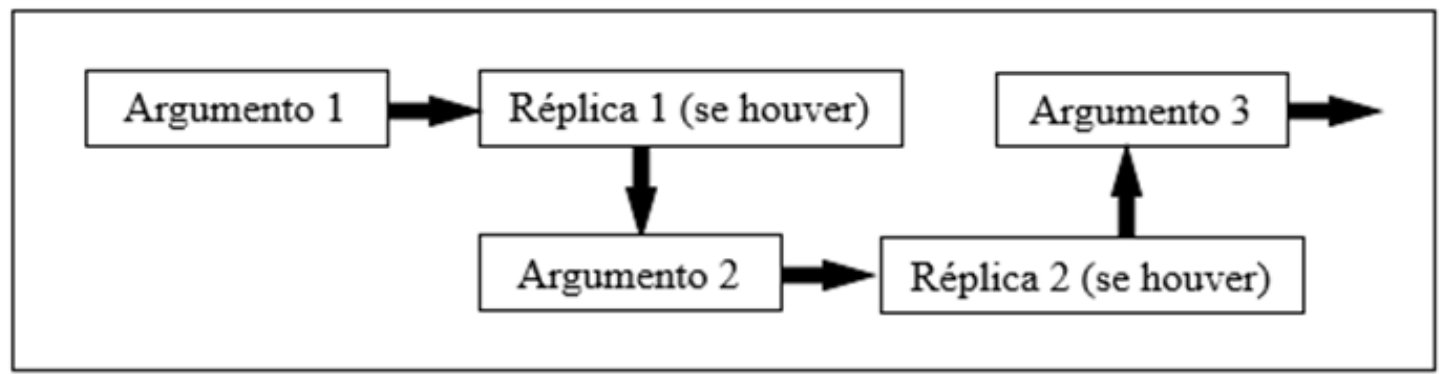

Fonte: Castro e Bolite-Frant (2011, p. 78) 


\section{Análise do discurso docente no contexto do curso de Pedagogia}

Apresentaremos uma possibilidade de articulação da Teoria da Argumentação, por meio do MEA, no contexto dos cursos de Pedagogia de universidades públicas e privadas do Rio de Janeiro. Destacamos que o desenvolvimento das análises com base nessa técnica é um processo bastante extenso e minucioso. Portanto, apresentaremos uma síntese desse processo, estruturada de forma a facilitar a compreensão do esquema argumentativo elaborado pelos professores entrevistados ao argumentarem acerca da formação pedagógica.

Participaram da pesquisa 10 professores que ministram variadas disciplinas em cursos de Pedagogia de três universidades do Rio de Janeiro. Foram identificadas, no discurso dos professores entrevistados, quatro controvérsias que giram em torno da formação pedagógica, a partir das quais eles elaboram suas defesas.

A primeira está relacionada a lacunas existentes na formação docente, que, segundo os participantes, vêm contribuindo para que o curso de Pedagogia permaneça sem uma clara definição de sua identidade (tese 1). Essa defesa pode ser verificada a partir do esquema a seguir:

Figura 3 - Esquema argumentativo para a tese 1

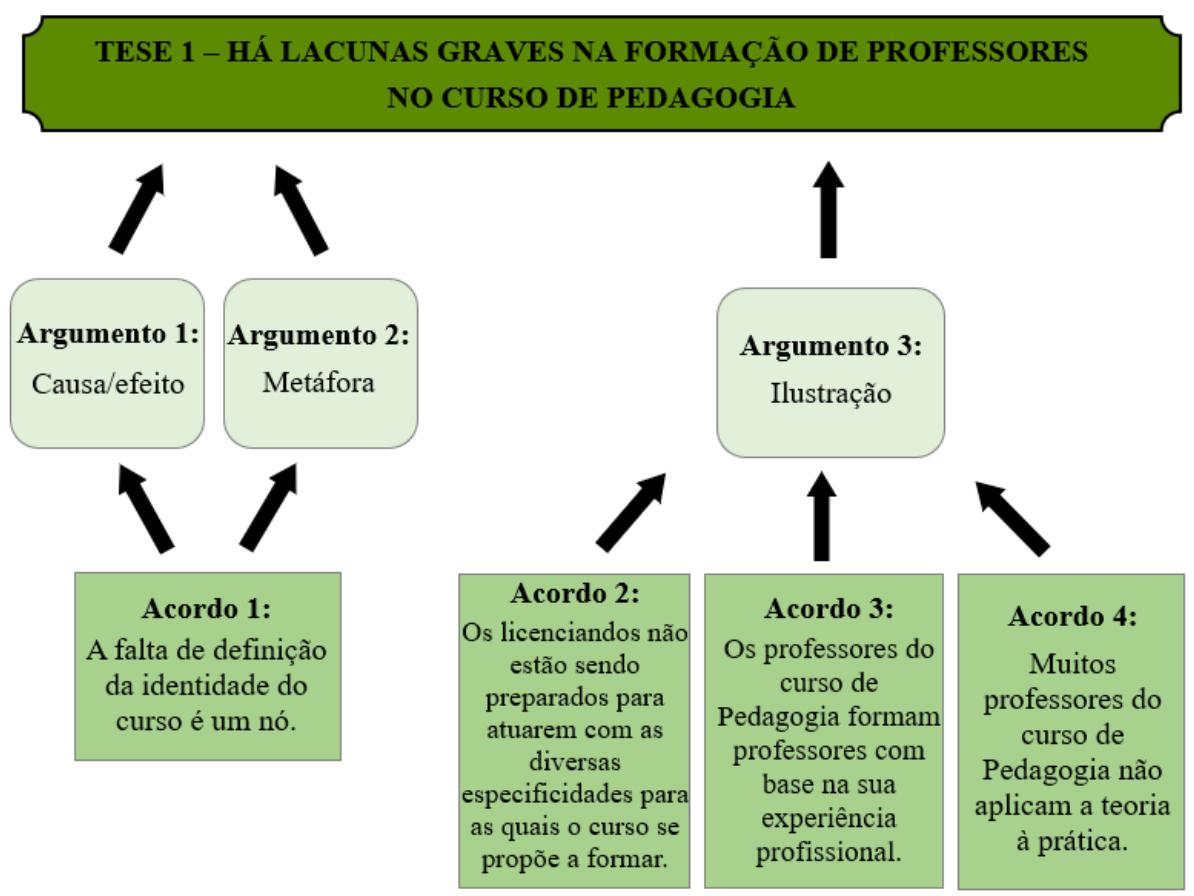

Fonte: Autoria própria

Embora a legislação atual para o curso de Pedagogia reconheça a docência como centro da formação, é válido lembrar que ela é considerada em sentido bastante amplo, 
abarcando a formação para atuação na Educação Infantil, nos Anos Iniciais do Ensino Fundamental, incluindo-se a modalidade da Educação de Jovens e Adultos, e no curso Normal em nível médio. Além disso, são consideradas como parte da docência as habilidades referentes à gestão administrativa e pedagógica dos espaços escolares. O curso também se propõe a formar o pedagogo, englobando a compreensão da realidade educacional, tendo como referência os domínios de conhecimentos constitutivos da área, além do desenvolvimento de habilidades para intervir na realidade educacional.

A grande abrangência de formação a que se propõe o curso de Pedagogia gera discussões acerca de sua identidade. Os professores entrevistados apontam o fato de ainda não haver uma definição da identidade do curso de Pedagogia quanto ao seu perfil (acordo 1) devido à grande abrangência de formação proposta pelo curso, associando esse fato às lacunas (acordos 2, 3 e 4) existentes na formação do professor.

Visando dar ênfase à falta de definição da identidade do curso de Pedagogia, identificada no discurso dos professores, um dos entrevistados lança mão de uma metáfora, associando essa problemática a um nó. O termo utilizado faz referência a uma situação estática, que se apresenta como um obstáculo, sem garantia de que se consiga superá-lo. Assim, reproduz-se um modelo de formação sem delimitações precisas de seus objetivos.

A aplicabilidade das teorias estudadas pelos alunos do curso de Pedagogia também é uma questão fortemente abordada. Em diversos momentos das entrevistas, os professores problematizam a aplicabilidade dessas teorias e, embora apontem que são passíveis de aplicação (tese 2), sinalizam que muitas vezes não são aplicadas, uma vez que os próprios professores optam por não inserir prática às suas disciplinas teóricas. O desenvolvimento dessa argumentação pode ser verificado a partir do esquema a seguir:

Figura 4 - Esquema argumentativo para a tese 2

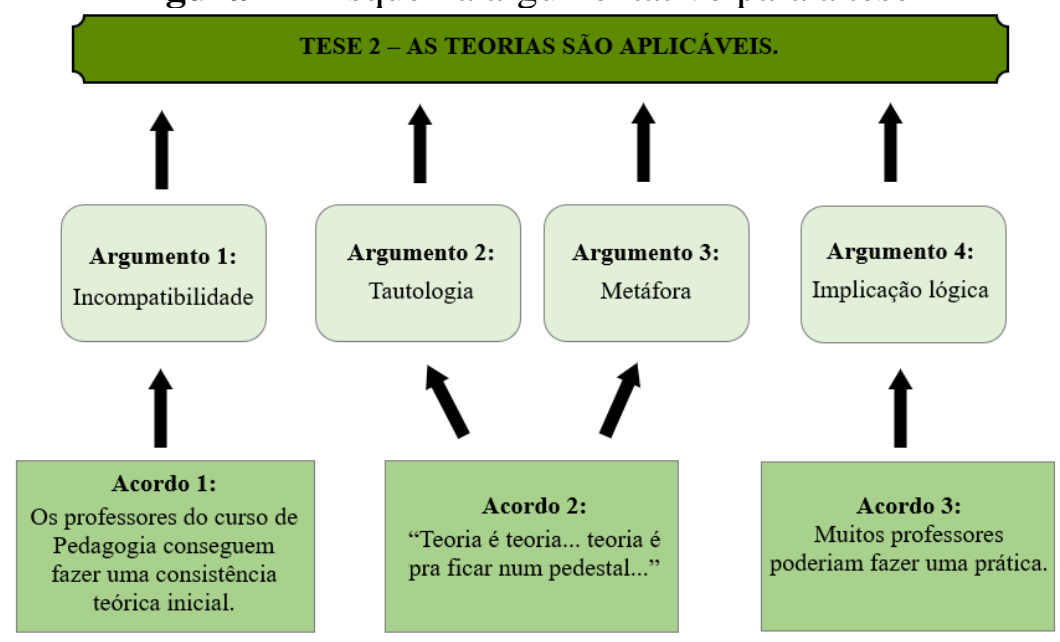

Fonte: Autoria própria 
Em seu discurso, os entrevistados afirmam que os professores de curso de Pedagogia conseguem desenvolver uma formação teórica consistente (acordo 1). No entanto, revelam que a aplicação da teoria "fica a desejar", sendo necessário que os próprios professores façam adaptações em suas disciplinas de maneira a transformar a teoria em prática aplicada para o licenciando.

Visando a reforçar essa defesa em relação à prática desenvolvida no curso de Pedagogia, um dos entrevistados lança mão de uma afirmação bastante categórica, de que "teoria é teoria" e, sendo assim, deve ficar em um "pedestal" (acordo 2). Para tal, argumenta, primeiramente, por meio de uma tautologia, utilizando o termo "teoria" como definição do que seria teoria. Embora o entrevistado faça uso de dois termos igualmente grafados para construir tal definição, o mesmo atribui a eles sentidos diferentes. $\mathrm{O}$ segundo é apresentado como algo divino, intangível.

Com o objetivo de explicar essa tautologia, dando maior sustentação à sua defesa, em busca da adesão de sua posição, o professor utiliza uma metáfora. Ele faz uso desse recurso persuasivo usando o termo "pedestal". O entrevistado se vale da imagem do pedestal para divinizar a teoria, atribuindo a ela características de algo que é tido como inquestionável. Dessa forma, ele reitera o discurso em relação à falta de aplicação da teoria à prática, que se fez presente no discurso de todos os entrevistados.

Assim como a distância entre teoria e prática no curso de Pedagogia permeia o discurso dos professores, a possibilidade de aplicação da teoria também está presente ao longo de toda a argumentação. E, para dar sustentação a essa defesa, os entrevistados afirmam que muitos professores poderiam "fazer uma prática" ao ministrarem suas disciplinas teóricas (acordo 3). No entanto, colocam tal afirmação no campo da escolha, referindo-se ao fato de muitos professores optarem por não fazê-la.

Convém destacar que a argumentação desenvolvida pelos entrevistados em relação à aplicabilidade da teoria à prática está baseada numa questão de opção, no campo da escolha do professor do curso de Pedagogia. Eles não compartilham do significado de que toda teoria, por si só, pressupõe prática e enfatizam que ela só é passível de aplicação uma vez que os professores optam por inserir prática à teoria. Assim, defendem que cabe ao professor adicionar prática às suas disciplinas teóricas (tese 3), o que é representado no esquema a seguir: 
Figura 5 - Esquema argumentativo para a tese 3

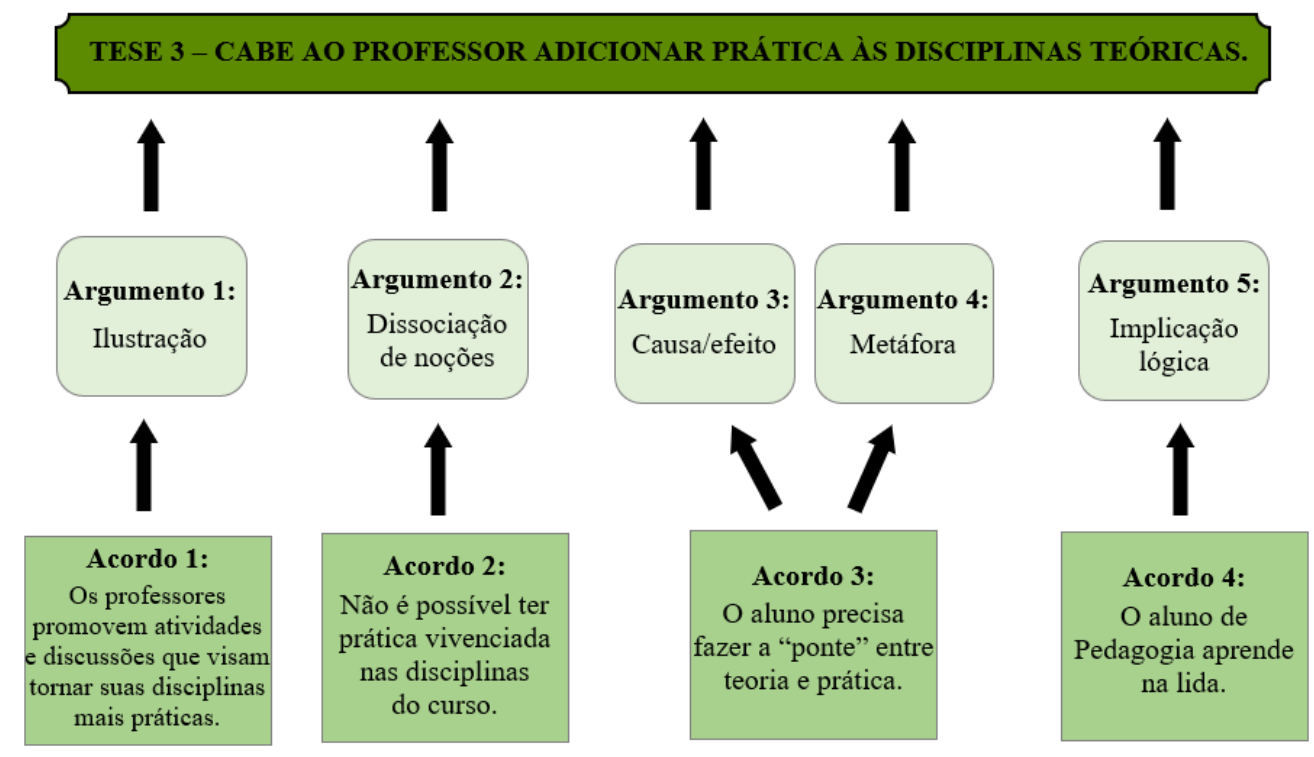

Fonte: Autoria própria

Fica bastante marcada, ao longo das entrevistas, a defesa em relação à tarefa do professor do curso de Pedagogia de adicionar prática às disciplinas teóricas. Cada entrevistado parece querer deixar registrado o cumprimento da sua parcela de responsabilidade por essa tarefa. Assim, em diversos momentos da entrevista, mencionam as ações que adotam ao ministrarem suas próprias disciplinas, visando tornar suas aulas mais práticas (acordo 1), para que o licenciando se sinta mais preparado para exercer a docência.

Demonstrando ter consciência de que sua tese (a defesa de que cabe ao professor adicionar prática às disciplinas teóricas) é associada por muitos educadores a algo que lhes parece ruim (a falta de prática nas disciplinas), alguns dos entrevistados buscam dissociá-la dessa ideia para que possam fazer com que seu auditório venha a aceitar sua tese mais adiante.

A noção de prática, apresentada como unitária, é dividida em dois termos: uma vivenciada e outra desenvolvida por meio da observação. Os professores defendem uma proposta de prática de discussão a partir da observação de situações de vivência da sala de aula, apresentando todas as qualidades dessa proposta, que é o que torna possível algo que os outros dizem ser impossível. No entanto, eles próprios, no decorrer da entrevista, afirmam não ser, de fato, prática o que realizam (acordo 2).

E, por assim ser, ao desenvolverem sua argumentação, alguns dos entrevistados se valem de uma metáfora bastante utilizada no campo da Educação: a "ponte". Eles associam o termo "ponte" à ligação que o licenciando deve fazer entre teoria e prática (acordo 3). 
Uma ponte liga dois lugares que se encontram naturalmente separados. Uma vez que os professores apontam essa necessidade de se construir uma ponte entre os conhecimentos teóricos e as práticas pedagógicas, deduz-se que um elemento está originalmente separado do outro. Esse recurso persuasivo enfatiza a falta de relação entre a teoria e a prática, mostrando serem dois assuntos distintos, que não se relacionam naturalmente, precisando de algo que estabeleça uma conexão entre eles. E essa tarefa recai sobre o licenciando, que, segundo apontam as entrevistas, aprende na "lida" (acordo 4), ou seja, no próprio exercício da profissão, "apesar da universidade", conforme registrado em suas falas.

Mesmo tendo havido uma série de mudanças na legislação para a formação de professores, o discurso dos entrevistados evidencia que permanece, no curso de Pedagogia, uma formação ampla e genérica, fundada nos aspectos teóricos, que não tem respondido aos desafios atuais. Embora alguns professores abordem essa questão de forma mais direta e outros busquem um caminho mais sinuoso, todos apontam que ainda existe bastante dificuldade em se promover mudanças efetivas no modelo do curso de Pedagogia (tese 4). O desenvolvimento dessa argumentação pode ser verificado a partir do esquema a seguir:

Figura 6 - Esquema argumentativo para a tese 4

\section{TESE 4 - É MUITO DIFÍCIL MUDAR O MODELO DO CURSO DE PEDAGOGIA.}
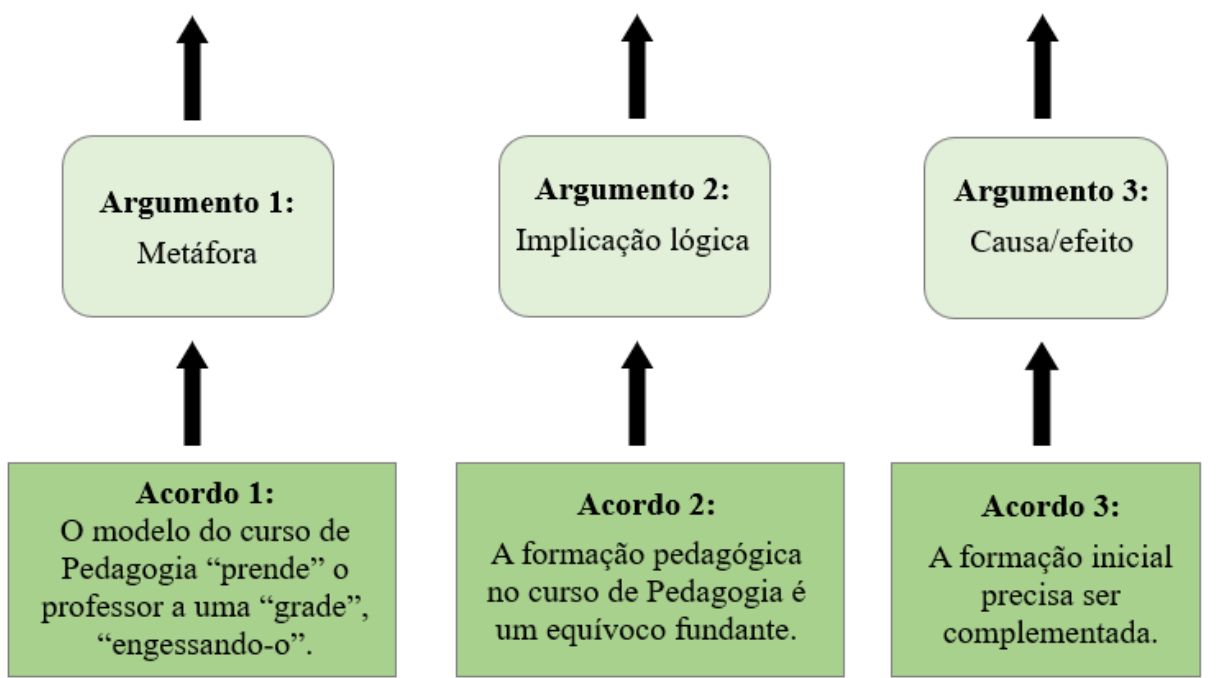

Fonte: Autoria própria

Embora os professores entrevistados tenham consciência das lacunas existentes no curso de Pedagogia, as quais já foram abordadas anteriormente, a dificuldade de estabelecer mudanças ainda é perceptível. Quando questionados acerca dos possíveis motivos dessa dificuldade, os entrevistados buscam elementos que possam expressar tal realidade. 
Para desenvolver a defesa em relação à dificuldade de mudar o modelo do curso de Pedagogia, os professores fazem uso de uma série de metáforas. Um professor faz alusão à grade curricular do curso, utilizando um jogo de palavras para destacar que essa "grade" é o que "prende" o modelo, fazendo com que seja muito difícil "mexer" nele. Compartilhando dessa ideia, outro entrevistado associa o professor do curso de Pedagogia a algo que está “engessado" (acordo 1).

Esse recurso é utilizado pelos professores com função persuasiva, a fim de associar o modelo de formação do curso de Pedagogia a algo estático. Eles buscam dar ênfase à dificuldade de mexer em tal modelo, de fazer alterações, o que, segundo eles, implicaria mexer com disciplinas, professores e horários.

Em seu jogo argumentativo, os professores fazem afirmações que vão da causa para o efeito e do efeito para a causa, num movimento contínuo de ida e volta, sendo um fator impedimento do outro e vice-versa. Segundo eles, porque o modelo do curso está engessado (causa), ele não muda (efeito); e porque não muda (causa), permanece engessado (efeito). Fazendo uso de mais um elemento metafórico para expressar tal realidade, outro professor se refere a esse modelo como um "círculo vicioso".

Associar o modelo do curso a um círculo vicioso foi o recurso que ele encontrou para dar ênfase a essa característica permanente de ações e consequências que resultam numa situação que parece sem saída: o efetivo preparo do professor que se forma no curso de Pedagogia para exercer a docência, ou seja, a sua formação pedagógica.

Fazendo uma reflexão sobre os possíveis motivos dessa situação, outro professor chega à conclusão de que trata-se de um "equívoco fundante". O termo por ele utilizado sintetiza as impressões dos demais professores entrevistados em relação à articulação entre teoria e prática. E ele o faz de maneira bastante categórica. Segundo o professor, a lógica do curso de Pedagogia é "um equívoco fundante", ou seja, o curso foi desenvolvido ao longo de todos estes anos tomando como base o "equívoco" que o constituiu: a separação entre teoria e prática (acordo 2). A argumentação é desenvolvida por meio da seguinte implicação lógica: os professores associam a formação pedagógica no curso de Pedagogia à articulação entre teoria e prática. Se a articulação entre esses elementos é um equívoco fundante, então, a formação pedagógica é um equívoco fundante.

Uma vez que a formação pedagógica desenvolvida no curso de Pedagogia é insuficiente e tendo em vista a dificuldade de se promover mudanças efetivas no curso, os professores entrevistados apontam um meio de compensar essa falta. Assim, a formação 
continuada é apresentada por eles como uma possibilidade de complementação da formação pedagógica do professor (acordo 3).

Embora tenhamos apresentado separadamente a análise das quatro teses defendidas pelos professores entrevistados, a título de facilitar a compreensão do jogo argumentativo por eles desenvolvido ao abordar a formação pedagógica desenvolvida no curso de Pedagogia, elas estão diretamente relacionadas.

As lacunas existentes na formação são o ponto de partida para que os entrevistados façam sucessivas implicações, que indicam como representam a formação pedagógica no atual modelo de formação do curso de Pedagogia. Ao longo da realização das entrevistas, foi possível perceber a ênfase que os professores dão à falta de articulação entre as teorias e as práticas pedagógicas no curso de Pedagogia. Em praticamente todos os assuntos abordados, eles se voltavam para a falta de articulação entre esses elementos. Os entrevistados associam a formação pedagógica no curso de Pedagogia à articulação entre teoria e prática, que, conforme seu discurso aponta, é insuficiente para o exercício da docência, precisando ser complementada pela formação continuada.

\section{Considerações finais}

A partir das reflexões teóricas realizadas da análise argumentativa empreendida, entendemos que o atual modelo de formação ainda não constitui base de conhecimento que articule os conhecimentos teóricos às práticas pedagógicas que orientarão o futuro professor em sua atuação na Educação Infantil e dos Anos Iniciais do Ensino Fundamental, levando em conta suas especificidades.

Embora haja na literatura um consenso acerca da imprescindibilidade de alteração na estrutura do curso de Pedagogia, em que a docência constitua efetivamente o foco de atuação dos professores desse curso, essa é uma questão que ainda não foi solucionada. Por se tratar de uma dificuldade que se perpetua até os dias de hoje, em que práticas pedagógicas ainda se encontram cristalizadas, alicerçadas em um modelo tradicional de formação, é necessário promover maior discussão acerca dos fatores que vêm dificultando, atualmente, a implantação de possíveis mudanças.

Nesse sentido, defendemos uma proposta de formação de professores com base na Educação de cunho argumentativo, que valorize as diversas opiniões dos sujeitos e incentive a interrogatividade, a fim de chegar a acordos plausíveis, sendo passíveis de renovações sempre 
que necessário. Uma Educação argumentativa é aquela que não nega a problematização e que acolhe as questões trazidas pelos diferentes auditórios.

Consideramos que pensar numa Educação de abordagem argumentativa não é tarefa fácil, pois estamos vivendo em uma sociedade em que há cada vez menos disposição para ouvir o outro, considerar seus interesses, suas necessidades, inquietações e questões. Também observamos indivíduos que estão vivenciando um completo desânimo, que fazem uso do discurso da dificuldade, que vem, cada vez mais, reforçando o imobilismo, fruto do apego à tradição. Esse pano de fundo influencia a maneira como a formação de professores vem sendo desenvolvida no curso de Pedagogia em que esses indivíduos atuam, reproduzindo tais ações sociais.

Não podemos abrir mão de problematizar as demandas atuais para a formação de professores, nem entre o grupo de docentes, nem com os licenciandos, pois, por meio desse processo, é possível trilhar novos caminhos, renovando as reflexões - ou promovendo novas! - sobre um determinado assunto. Problematizar também é uma etapa indispensável no processo de aprendizagem, tanto para docentes quantos para discentes, já que o aprendizado decorre do confronto entre convicções e percepções acerca de diferentes assuntos.

\section{REFERÊNCIAS}

CASTRO, Monica Rabello et al. Análise das interações em educação: retórica, argumentação, comunicação e representações sociais. 1. ed. Nova Iguaçu: Marsupial, 2016. v. único. 137p.

CASTRO, Monica Rabello; MAIA, Helenice; ALVES-MAZZOTTI, Alda Judith. Representações sociais do trabalho docente: um olhar sobre a subjetividade do professor em sala de aula. Revista Educação e Cultura Contemporânea, Rio de Janeiro, v. 10, n. 22, p. 150-177, 2013. Disponível em: http://periodicos.estacio.br. Acesso em: 01 abr. 2020.

LEMGRUBER, Márcio Silveira; OLIVEIRA, Renato José de. Argumentação e educação: da ágora às nuvens. In: LEMBRUGER, Márcio Silveira; OLIVEIRA, Renato José de (Orgs.). Teoria da Argumentação e educação. Juiz de Fora: UFJF, 2011. p. 91-106.

MARCONI, Marina de Andrade; LAKATOS, Eva Maria. Metodologia do trabalho científico. 8. ed. São Paulo: Atlas, 2018.

MAZZOTTI, Tarso. Análise retórica e dialética de discursos acerca da Educação. Revista Educação e Cultura Contemporânea, Rio de Janeiro, v. 8, n. 17, p. 1-19, 2011. Disponível em: http://periodicos.estacio.br. Acesso em: 01 abr. 2020. 
MEYER, Michel. A problematologia como chave para a unidade da retórica. In: MEYER, Michel; CARRILHO, Manuel Maria; TIMMERMANS, Benoit. História da Retórica. Lisboa: Temas e Debates, 2002. p. 265-298.

OLIVEIRA, Renato José de. A ética no discurso pedagógico da atualidade. Niterói: Intertexto, 2011.

PATTON, M. Q. Qualitative research and evaluation methods. 3. ed. Thousand Oaks, California: Sage, 2002. Disponível em: http://www.sciepub.com/reference. Acesso em: 30 mar. 2020.

PERELMAN, Chaïm. Retóricas. 2. ed. São Paulo: Martins Fontes, 2004.

PERELMAN, Chaïm; OLBRECHTS-TYTECA, Lucie. Tratado da argumentação: a nova retórica. 6. ed. São Paulo: Martins Fontes, 2005.

\section{Como referenciar este artigo}

COSTA, Clara Corrêa da; OLIVEIRA, Helen Silveira Jardim de. Discursos docentes do curso de pedagogia: um olhar à luz da teoria da argumentação. Revista Ibero-Americana de Estudos em Educação, Araraquara, v. 15, n. 3, p. 1389-1407, jul./set. 2020. e-ISSN: 19825587. DOI: https://doi.org/10.21723/riaee.v15i3.13613

Submetido em: 19/11/2019

Revisões requeridas: 20/12/2019

Aprovado em: 29/01/2020

Publicado em: 20/02/2020 